\title{
Laser Transformation Hardening of Tempered 4340 Steel
}

\begin{abstract}
R.K. SHIUE and C. CHEN
$\mathrm{A} \mathrm{CO}_{2}$ laser with a fixed laser power of $1.8 \mathrm{KW}$ was employed to harden the surface of some AISI 4340 steel specimens, with a scan rate from 5 to $10 \mathrm{~mm} / \mathrm{s}$. The influence of scan rates and tempering treatments of the alloy on the hardness profile and microstructure of the laserhardened zone was analyzed. Microstructures in the hardened zone consisted of mainly lath and twinned martensites. However, depending on the scan rate, autotempered martensite has also been found. In the transition zone of laser-treated specimens, partially dissolved carbides with austenite envelopes and/or austenite islands in a matrix of martensite were observed. The time required for complete carbide dissolution into austenite during laser treatment depended on the tempering conditions. A lower tempering temperature of the alloy produced a deeper hardened zone and a narrower transition zone in the hardness profile. A simple mathematical estimation of the hardness profile, based on the carbon diffusion distance in austenite, was performed. The calculated results are in reasonably good agreement with the measured hardness profiles and the microstructural observations in the laser transformation hardening process.
\end{abstract}

\section{INTRODUCTION}

LASER transformation hardening of steels is one of many successful applications in laser material processing. It is characterized by a very short interaction time, with the intense energy density which accelerates the cooling rate of the laser-impinged area. When the laser beam is removed, rapid self-quenching by conduction of heat into the bulk material causes the martensitic transformation in the surface layer. The process is suitable for selective surface treatments and is primarily used in steels with sufficient hardenability for improved wear resistance and fatigue strength. ${ }^{[1,2]}$

The mechanism for laser transformation hardening involves the formation of austenite on the heating cycle and then the transformation to martensite upon cooling. It is known that the microstructure of the material exerts a great influence on the formation of austenite during laser processing. ${ }^{[3]}$ The case depth is deeper for AISI 4150 specimens with bainitic and tempered martensitic structures than for those with pearlitic and spheroidized structures. ${ }^{[4]}$ The extent of the laser-hardened zone for specimens with various microstructural features can be related to the size and distribution of carbides in the steel. Finer and more evenly distributed carbides would produce a better hardening effect. ${ }^{[3,4]}$

Molinder ${ }^{[5]}$ conducted investigations on a hypereutectoid steel with widely spaced carbides and observed that the growing austenite occasionally enveloped the carbides. Continued dissolution of carbides then took place by carbon diffusion through the austenite envelope ${ }^{[6,7]}$ in the austenite temperature range. Finally, the growing austenite regions impinged and the complete transfor-

R.K. SHIUE, formerly Graduate Research Assistant, Institute of Materials Science and Engineering, National Taiwan University, is Engineer, Taiwan Power Company, Taichung, Taiwan, Republic of China. C. CHEN, Professor, is with the Institute of Materials Science and Engineering, National Taiwan University, Taipei, Taiwan 10764, Republic of China.

Manuscript submitted January 30, 1991. mation to austenite was achieved. Speich et al. ${ }^{[8]}$ studied austenite formation during intercritical annealing of 1.5 pct Mn dual-phase (ferrite and pearlite) steels, indicating that the time for complete dissolution of pearlite to form austenite was very short $(0.2$ to $200 \mathrm{~ms})$ at temperatures between $780^{\circ} \mathrm{C}$ and $900{ }^{\circ} \mathrm{C}$. After the dissolution of pearlite, further growth of austenite into ferrite was controlled by the carbon diffusion in the austenite at high temperatures of $850{ }^{\circ} \mathrm{C}$ to $900{ }^{\circ} \mathrm{C}$. At low temperatures $\left(740{ }^{\circ} \mathrm{C}\right.$ to $\left.780^{\circ} \mathrm{C}\right)$, the growth of austenite was controlled by $\mathrm{Mn}$ diffusion in ferrite, which required a much longer time (4 to 24 hours) to proceed. Apparently, the thermal cycles (at various depths) of laser-treated specimens included all of the possible reactions at corresponding temperature ranges, as mentioned above. Ashby and Easterling ${ }^{[9]}$ have analyzed the temperature as a function of time at various depths for laser surface treatments. In their study, approximate solutions to the heat flow equations were combined with kinetic models to predict the near-surface hardness and structures of lasertreated steels.

The purpose of this study was to investigate the detailed microstructural features in the laser-treated regions of AISI 4340 steel that had originally been tempered at different temperatures. A simple mathematical calculation was used to estimate the diffusion distance of carbon in austenite during the laser-hardening process. The calculated results were then compared with the hardness values and the observed microstructures on laser-hardened zones.

\section{MATERIALS AND EXPERIMENTAL PROCEDURE}

The alloy used in this investigation was AISI 4340 steel in the form of a 10-cm-diameter bar. The chemical composition of the steel in weight percent was $0.39 \mathrm{C}$, $1.68 \mathrm{Ni}, 0.64 \mathrm{Cr}, 0.15 \mathrm{Mo}, 0.67 \mathrm{Mn}, 0.22 \mathrm{Si}, 0.017 \mathrm{P}$, and $0.014 \mathrm{~S}$. Samples were sliced from the bar and heat-treated to obtain tempered martensitic structure with various carbide sizes, i.e., fine, medium, and coarse carbides. 
Table I. Heat-Treatment Procedures and Microstructural Features of the Specimens Prior to the Laser Treatment

\begin{tabular}{cll}
\hline Specimen ID & \multicolumn{1}{c}{ Tempering Procedures* } & \multicolumn{1}{c}{ Microstructures } \\
\hline T-400 & $204^{\circ} \mathrm{C}\left(400^{\circ} \mathrm{F}\right) / 2 \mathrm{~h}+\mathrm{AC}$ & tempered martensite with fine carbides \\
$\mathrm{T}-800$ & $427^{\circ} \mathrm{C}\left(800^{\circ} \mathrm{F}\right) / 2 \mathrm{~h}+\mathrm{AC}$ & tempered martensite with medium carbides \\
$\mathrm{T}-1200$ & $649^{\circ} \mathrm{C}\left(1200^{\circ} \mathrm{F}\right) / 2 \mathrm{~h}+\mathrm{AC}$ & tempered martensite with coarse carbides \\
\hline
\end{tabular}

${ }^{*}$ All specimens were solution-treated at $845^{\circ} \mathrm{C} / 1 \mathrm{~h}$ and then oil-quenched.

Table I gives the heat-treatment procedures and microstructural description of the specimens. All samples were machined to the dimension of $80 \times 25.4 \times 12.7 \mathrm{~mm}$ block with a surface finish of $3 \mu \mathrm{m}$. The decarburized surface layer of all heat-treated samples was removed by grinding. The thickness $(12.7 \mathrm{~mm})$ of the test block was larger than the depth of the heat-affected zone to ensure no perturbations in the mass quench. All specimens used in this study were coated with Krylon ultraflat black paint for improved energy absorption.

Laser transformation hardening experiments were performed by a Spectra-Physics laser. This laser generates a continuous wave $\mathrm{CO}_{2}$ laser beam at a $10.6 \mu \mathrm{m}$ wavelength, with an output power up to $2.5 \mathrm{KW}$. A defocused laser beam (spot size $\sim 15 \mathrm{~mm}$ in diameter) with nearly Gaussian energy profile was employed throughout the experiment. Beam power was adjusted to produce $1.8 \mathrm{KW}$ on the surface of the specimen as calibrated by the power meter. Tests were carried out at several scan rates $(5,6.7,8.3$, and $10 \mathrm{~mm} / \mathrm{s})$ in order to vary the energy density of the laser beam.

Hardness measurements along the case depth below the surface were made with a Vickers microhardness tester. The Vickers hardness was converted to $R_{c}$ for convenience. Optical microscopy was employed to identify distinct regions of the subsurface microstructure after laser treating. For detailed microstructural analyses, transmission electron microscopy (TEM) specimens were sectioned in thin slices parallel to the laser-treated surface. A series of steps combining mechanical grinding and chemical thinning processes were then applied in order to obtain the TEM thin foils (thickness $<0.1 \mathrm{~mm}$ ) at the desired depth within $0.1 \mathrm{~mm}$ accuracy. The procedure was very time consuming and involved repeated measurements in order to ensure the thickness range. The thin foils were prepared by a standard jet-polisher and examined with a JEOL-2000 EX microscope operated at $200 \mathrm{KV}$.

\section{RESULTS}

The microstructure of 4340 steel prior to laser treatment consisted of tempered martensite with various carbide sizes. Figure 1 illustrates that the carbide size increased and its morphology changed as the tempering temperature rose. If the complete austenitization was mainly controlled by carbon diffusion in austenite, the characteristic diffusion distance would be half of the average interparticle spacing. The laser surface hardening process is characterized by the fast heating and cooling cycles. Factors such as local chemistry, structure, and thermal cycle are also important variables in the determination of final transformation products and the case depth of the laser-treated steel.
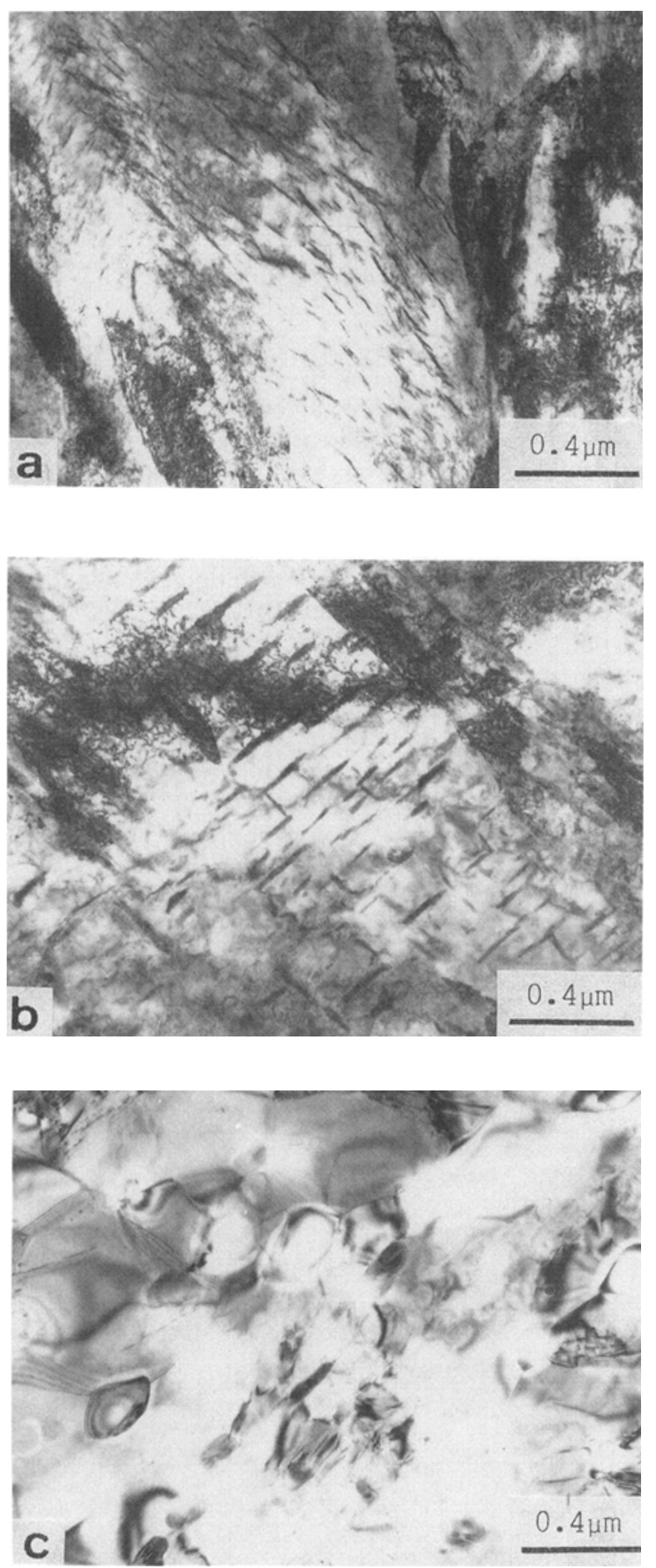

Fig. 1-TEM micrographs of the specimens preceding laser treatment: (a) T-400, (b) T-800, and (c) T-1200 specimens. 


\section{A. Microhardness}

A typical cross section (perpendicular to the scanning direction) of a laser-treated specimen irradiated by an approximately Gaussian beam is shown in Figure 2(a). The dark etching area represents the laser-hardened zone, where a distinct microstructural change has occurred. Figure 2(b) is the temperature distribution of the lasertreated specimen by computer simulation using a Gaussian beam. The isothermal of $\mathrm{Ac}_{3}$ matches well with the boundary (white line) of the laser-hardened zone. The melting as predicted by the simulation, however, was absent in the central region of the laser-treated specimen.

Microhardness measurements were made at the center of the hardened zone with 0.02 to $0.5 \mathrm{~mm}$ increments down to the surface, until the hardness of the base metal was reached. Figures 3(a) through (c) are the hardness profiles of laser-hardened T-400, T-800, and T-1200 specimens, respectively. Microhardness results clearly indicate that the depth of hardened zones increases and the surface hardness decreases as the scan rate decreases. Figure 4 demonstrates the influence of tempering temperature on the depth of hardened zones. The hardness curve usually can be divided into four regions (see T-800 specimen for example), as indicated in Figure 4. Region $\mathrm{AB}$ is the hardened zone, region $\mathrm{BC}$ is the transition zone in which the partial transformation occurred, region $\mathrm{CD}$ is the overtempered zone, and region $\mathrm{DE}$ is the heat-unaffected base metal. It is important to note
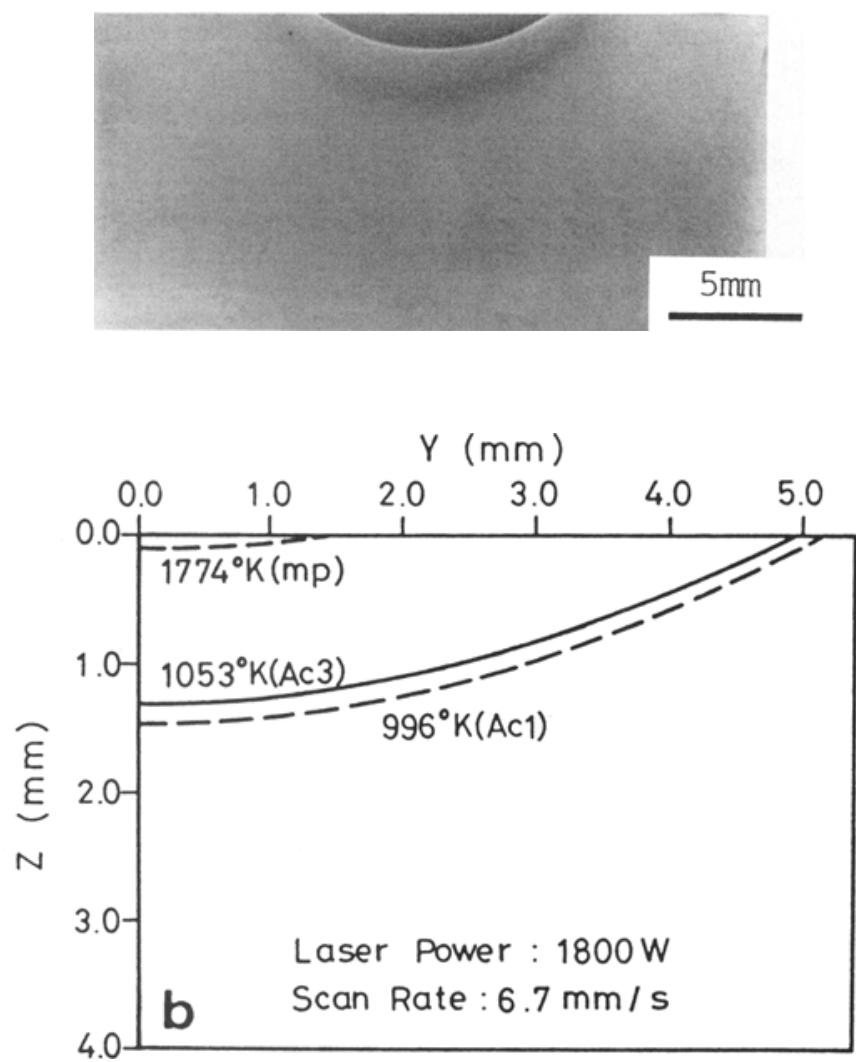

Fig. 2-The cross section of a typical laser-treated specimen with a scan rate of $6.7 \mathrm{~mm} / \mathrm{s}$. (a) Metallograph showing the hardened zone (dark area) developed by a nearly Gaussian beam and $(b)$ the temperature distribution computed by mathematical simulation using a Gaussian beam.
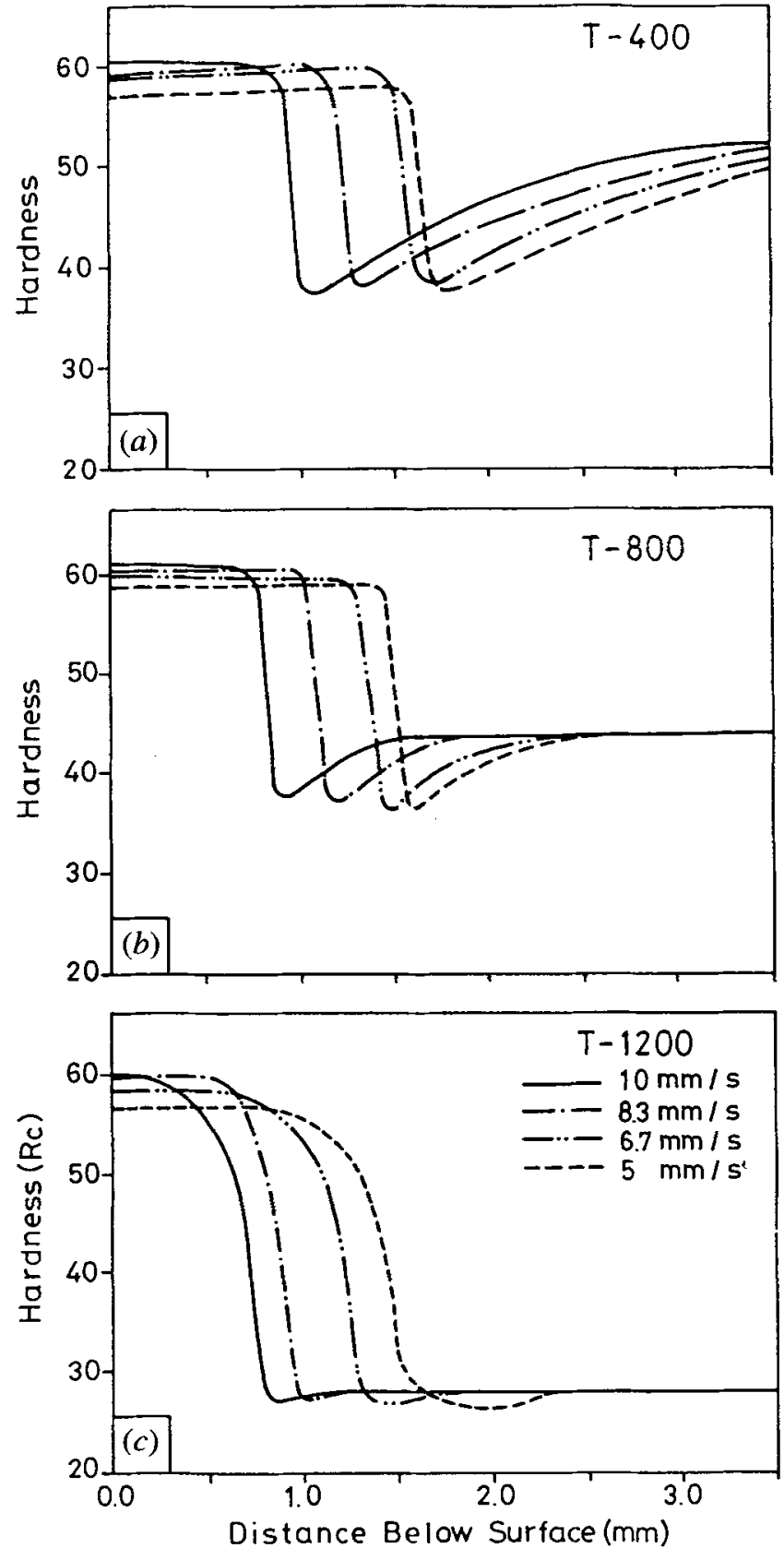

Fig. 3-Hardness as a function of depth below the surface of (a) T-400, (b) T-800, and (c) T-1200 laser-treated specimens.

that the transition zone became less steep as the tempering temperature of specimens increased. On the other hand, decreasing the tempering temperature resulted in a larger overtempered zone. For the specimens tempered at $649^{\circ} \mathrm{C}\left(1200^{\circ} \mathrm{F}\right)$, a very limited region of the overtempered zone was observed (Figure 4). Figure 4 also reveals that the lower the tempering temperature of the specimen, the deeper the hardened zone obtained.

\section{B. Microstructures of the Laser-Treated Steel}

Transmission electron microscopy studies have been performed on T-800 specimens with the laser processing speed of $5 \mathrm{~mm} / \mathrm{s}$. Figures 5 (a) through (c) are micrographs displaying the microstructures in depths 0.1 to 


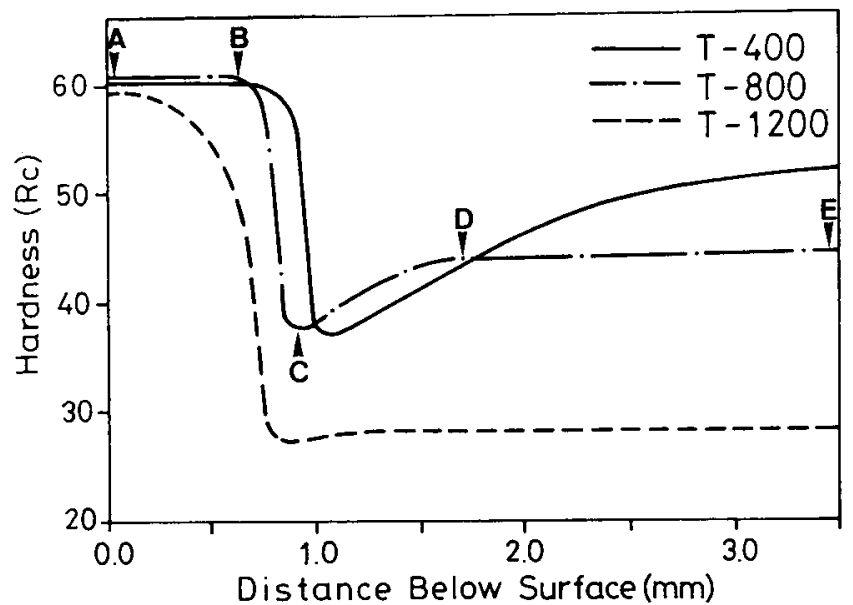

Fig. 4-The effect of tempering temperature on the hardness profiles in laser transformation hardening experiments. Scan rate $=10 \mathrm{~mm} / \mathrm{s}$.

$0.2 \mathrm{~mm}$ below the surface. The structures consist of lath martensite (dislocated martensite), plate martensite (twinned martensite), and autotempered martensite. These structures were also compared with those of the conventional heat-treated specimens $\left(850^{\circ} \mathrm{C} / 1 \mathrm{~h}+\right.$ oil-quenched); however, no significant difference has been found between them. The structures in depths between 1.4 and $1.5 \mathrm{~mm}$ revealed the similar microstructures, as shown in Figure 5, but the sizes of martensite lath and twin (Figure 6) were generally reduced. The microstructure in the layer of 0.1 to $0.2 \mathrm{~mm}$ below the surface for specimens which were laser-treated at $10 \mathrm{~mm} / \mathrm{s}$ was also examined. It was found that smaller martensite lath with less predominant autotempering effect could be obtained by increasing the scan rate, i.e., by increasing the cooling rate or reducing the heat input.

The transition zones in T-400 (Figure 3(a)) and T-800 (Figure 3(b)) specimens were too narrow to be cut into thin slices for structural analyses. The structures in the transition zone were analyzed only for $\mathrm{T}-1200$ specimens, owing to the existence of wide transition zones available for TEM studies. Figure 7 shows the micrographs of thin foil taken from 0.67 to $0.77 \mathrm{~mm}$ below the surface of a T-1200 specimen which was laser-treated at $10 \mathrm{~mm} / \mathrm{s}$. The microstructure was composed mainly of lath martensite with retained austenite existing at the interlath boundaries, carbide interface (in the form of austenite envelopes surrounding the carbide), and prior carbide locations. These structural features are quite unusual and could not be obtained in the conventional heattreatment process. From the shape of the austenite film (an envelope surrounding the carbide), it is obvious that austenite was originally nucleated at the interface between the carbide particle and martensite (or ferrite) matrix.

\section{DISCUSSION}

\section{A. Effect of Scan Rate on Hardness}

Figure 3 clearly illustrates that the depth of the hardened zone increases with decreasing scan rate. Under the condition of complete austenitization, the reduction of the scan rate increases the case depth and decreases the
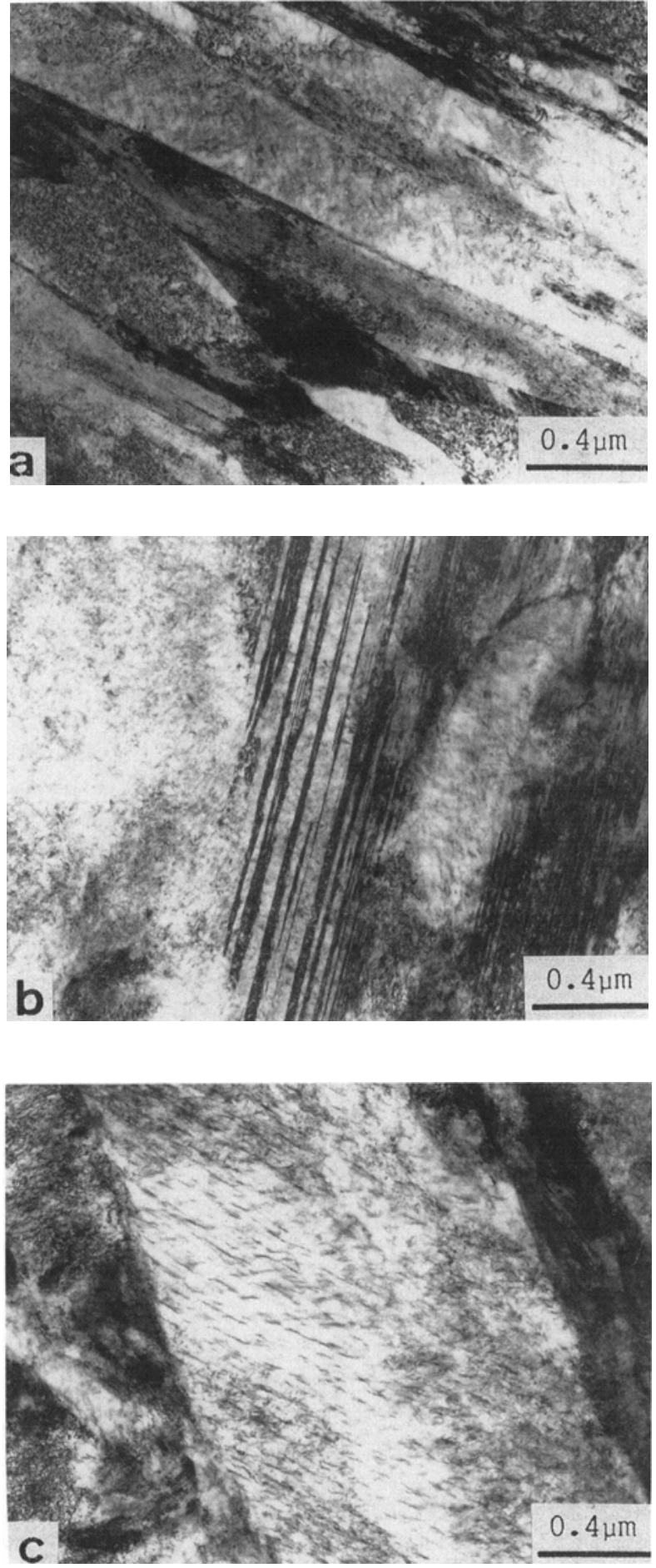

Fig. 5-The microstructures of the T-800 specimen at 0.1 to $0.2 \mathrm{~mm}$ below the laser-treated surface: $(a)$ lath, $(b)$ twinned, and (c) autotempered martensites. Scan rate $=5 \mathrm{~mm} / \mathrm{s}$.

surface hardness of laser-treated specimens. This is because with a low scan rate, the reaction time for austenitization and the heat flux to the surface were increased, resulting in an increase in the size (both depth and width) of the hardened zone upon self-quenching. The increase of the surface temperature with decreasing scan rate caused a decrease in surface hardness. The higher austenitization temperature, which gave a larger austenite grain size, 

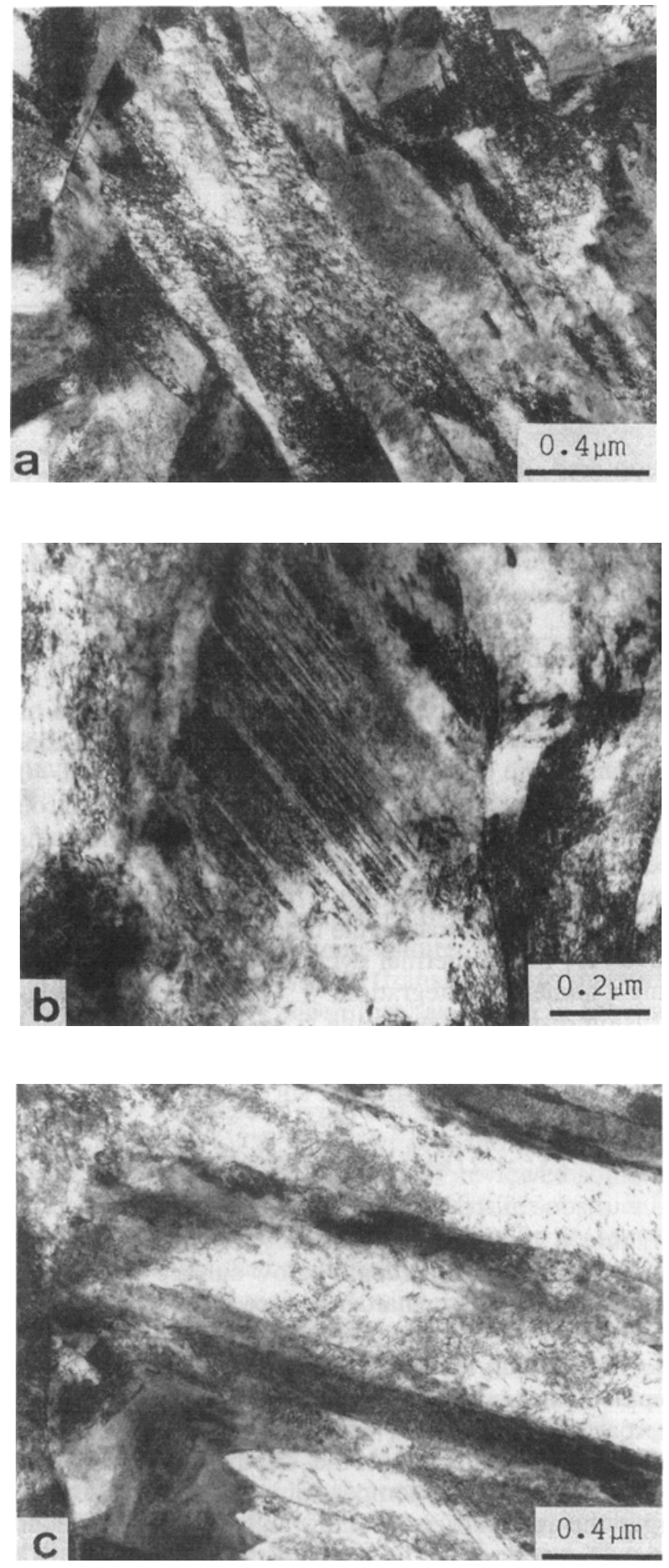

Fig. 6-The microstructures of the T-800 specimen at 1.4 to $1.5 \mathrm{~mm}$ below the laser-treated surface: $(a)$ lath, $(b)$ twinned, and (c) autotempered martensites. Scan rate $=5 \mathrm{~mm} / \mathrm{s}$.

induced a lower hardness of martensite upon cooling. It was reported that the larger prior austenite cell would result in a lower hardness of martensite. ${ }^{[10,11]}$ The lower scan rate resulted in the larger martensite sizes (lath and twin) in the hardened layer, so that the surface hardness decreased. Furthermore, the more pronounced autotempering effect at low scan rates also contributed to the lower surface hardness. Although the increase in the scan
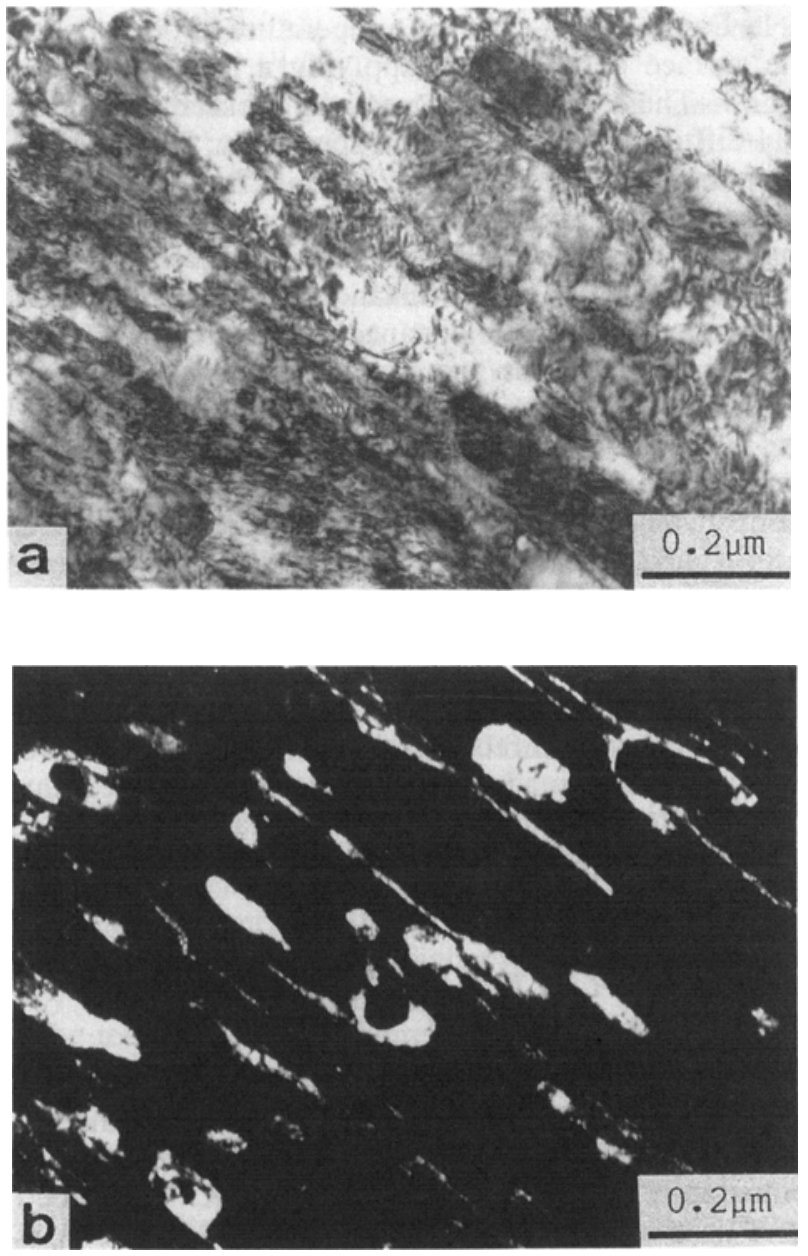

Fig. 7-TEM micrographs of T-1200 specimens at 0.67 to $0.77 \mathrm{~mm}$ below the laser-treated surface. Scan rate $=10 \mathrm{~mm} / \mathrm{s}$. (a) The brightfield image and $(b)$ the dark-field image of a (002) austenite reflection showing the austenite at the interlath boundaries, carbide interfaces, and prior carbide locations.

rate slightly raised the surface hardness, this was not the case for those samples containing large carbides such as $\mathrm{T}-1200$ specimens. The cause of this singularity is ascribed to insufficient austenitization, and the incomplete austenitization caused by an excessively high scan rate is discussed in Section C. In addition to the factors discussed above, the compressive residual stresses remaining in the hardened layer might also affect the surface hardness in the laser treatment. ${ }^{[12,13]}$

\section{B. Effect of Thermal Cycle}

If a defocused beam with a radius $r_{b}$ (defined as the distance from the beam center at which the intensity has fallen to $1 / e$ or $36.8 \mathrm{pct}$ of the peak value) moves on the surface of a specimen, the temperature distribution in the plane perpendicular to the surface through the centerline of the beam can be expressed as ${ }^{[9]}$

$$
T(z, t)=T_{0}+\frac{A q / v}{2 \pi \lambda\left(t\left(t+t_{0}\right)\right)^{1 / 2}} \exp \left\{-\frac{\left(z+z_{0}\right)^{2}}{4 a t}\right\}
$$


In Eq. [1], $T(z, t)$ is the temperature at depth $z$ below the surface derived from applying a laser power $q$ for time $t$. The terms $\lambda$ and $a$ are the thermal conductivity and diffusivity of the steel, respectively; $T_{0}$ is the initial temperature of specimens, $25^{\circ} \mathrm{C} ; A$ is the absorptivity of the surface; and $v$ is the velocity of the moving specimen (or scan rate). The constant $t_{0}$ represents the time for heat to diffuse over a distance of beam radius $r_{b}$. The length $z_{0}$ measures the distance over which heat can diffuse during the beam interaction time $r_{b} / v$.

Krylon flat black paint was employed by Kou et al..$^{[14]}$ and Sandven ${ }^{[15]}$ to enhance the absorption of the laser beam on the surface of the specimen. In their experiments, values of the absorptivity at the sample surface, $0.84^{[14]}$ and $0.85,^{[15]}$ were used. In this study, the same paint was used to coat the surface and an absorptivity of 0.85 was chosen in the temperature calculation. The material properties for carbon steels used by Ashby and Easterling ${ }^{[9]}$ were also employed. Both $r_{b}$ and $z_{0}$ are difficult to measure directly from the experiment. Several assumptions are made in order to estimate these values. The peak temperature $\left(T_{s}\right)$ on the surface after being irradiated by a stationary beam of intensity $q / \pi r_{b}^{2}$ is given by ${ }^{[9]}$

$$
T_{s}-T_{0}=\frac{2 A q}{\pi^{3 / 2} r_{b}^{2} \lambda}\left(\frac{a r_{b}}{v}\right)^{1 / 2}
$$

In the case of the scan rate $5 \mathrm{~mm} / \mathrm{s}$, a slightly localized melting was observed at the centerline of the lasertreated region. The assumption was then made that a peak temperature on the centerline was $1774 \mathrm{~K} .{ }^{[9]} \mathrm{A}$ value for $r_{b}$ of $5.31 \mathrm{~mm}$ is obtained from Eq. [2]. Since $z_{0}$ is a function of the laser power and the scan rate, the calculation of $z_{0}$ for various scan rates at a fixed power of $1.8 \mathrm{KW}$ was performed on T-400 specimens. The selection of T-400 was due to the fact that the complete carbide dissolution could readily be achieved in the laser surface-hardening process. The case depth of the hardened zone (Figure 3(a)) is assumed to be that where a minimal temperature of $\mathrm{Ac}_{3}$ was experienced in the thermal cycle. The depth of hardened zones and the corresponding $z_{0}$ values for various scan rates at a fixed laser power are listed in Table II. These values were used to check the location of overtempered zones for the same specimens used in the calculation. It is presumed that the highest temperature in the overtempered zone, as indicated by $\mathrm{C}$ in Figure 4, was $\mathrm{Ac}_{1}$ in the laser-treatment process. The distance $M$ from the surface to the $\mathrm{C}$ position (where the hardness is the lowest) for T-400 specimens with various scan rates was measured. Table III is the comparison of $M$ values by the theoretical calcu-

Table II. Depths of the Hardened Zones and $z_{0}$ Values for Laser-Treated Specimens at Various Scan Rates

\begin{tabular}{ccc}
\hline $\begin{array}{c}\text { Scan Rate } \\
(\mathrm{mm} / \mathrm{s})\end{array}$ & $\begin{array}{c}\text { Depth of the } \\
\text { Hardened Zone }(\mathrm{mm})\end{array}$ & $z_{0}(\mathrm{~mm})$ \\
\hline 5 & 1.55 & 1.97 \\
6.7 & 1.30 & 1.54 \\
8.3 & 1.00 & 1.38 \\
10 & 0.80 & 1.25 \\
\hline
\end{tabular}

Table III. Comparison of $M^{*}$ Values between the Theoretical Calculation and the Experimental Measurement for T-400 Specimens

\begin{tabular}{ccc}
\hline $\begin{array}{c}\text { Scan Rate } \\
(\mathrm{mm} / \mathrm{s})\end{array}$ & $\begin{array}{c}\text { Calculated } \\
M(\mathrm{~mm})\end{array}$ & $\begin{array}{c}\text { Measured } \\
M(\mathrm{~mm})\end{array}$ \\
\hline 5 & 1.75 & 1.75 \\
6.7 & 1.47 & 1.60 \\
8.3 & 1.15 & 1.25 \\
10 & 0.97 & 1.00 \\
\hline
\end{tabular}

${ }^{*} M$ - the distance from the surface down to a location where the hardness decreased to a minimum value in the hardness profile.

lation and the experimental measurement for $\mathrm{T}-400$ specimens, in which the measured and the predicted $M$ values are in good agreement. Therefore, it is believed that the assumptions made in the calculation of $r_{b}$ and $z_{0}$ are reasonable.

\section{Carbon Diffusion in Laser-Hardening Processes}

The original (starting) microstructure of the steel has a great influence on the depth of the laser-hardened zone. Finer and more evenly distributed carbides, as in T-400 specimens, produce a deeper case-hardening effect due to a shorter carbon diffusion distance during processing. Because the diffusivity of carbon in austenite varies with temperature, the characteristic diffusion distance $S$ can be calculated by estimating the time period $\left(t_{2}-t_{1}\right)$ stayed above $A c_{1}$ in the thermal cycle of laser processing. By using a numerical integration, ${ }^{[16,17]}$ the theoretical carbon diffusion distance in austenite $\left(Q=1.35 \times 10^{5} \mathrm{~J} / \mathrm{mole}\right.$ and $\left.D_{0}=1 \times 10^{-5} \mathrm{~m}^{2} / \mathrm{s}^{[9]}\right)$ can be calculated at varied depths below the laser-treated surface by Eq. [3]:

$$
S^{2}=2 D_{0} \int_{t_{1}}^{t_{2}} \exp (-Q / \mathrm{R} T(t)) d t
$$

Figure 8 is the relationship between the carbon diffusion distance and the depth below surface measured at the center of the laser-hardened area for specimens with several scan rates. It indicates that the diffusion distance of carbon rapidly decreased as the depth increased. The complete austenitization could not be obtained if the interparticle spacing of carbides was less than half the diffusion distance in the depths concerned. The higher the tempering temperature of the specimen, the larger the interparticle spacing and the longer the diffusion distance required for complete austenitization. The average interparticle spacing of carbides is approximately $0.06,0.14$, and $0.9 \mu \mathrm{m}$ for $\mathrm{T}-400, \mathrm{~T}-800$, and $\mathrm{T}-1200$ specimens, respectively. The dots in Figure 8 represent the predicted diffusion distance at different depths obtained by measuring from the hardened zones in Figure 3 for $R_{c}$ greater than 58. These results reveal that the predicted diffusion distance and half of the interparticle spacing of carbides are in reasonable agreement for various scan rates of the specimens.

\section{Microstructures in the Laser-Hardened Zone}

Equation [1] indicates that the near-surface layer experienced a higher temperature and a longer interaction 


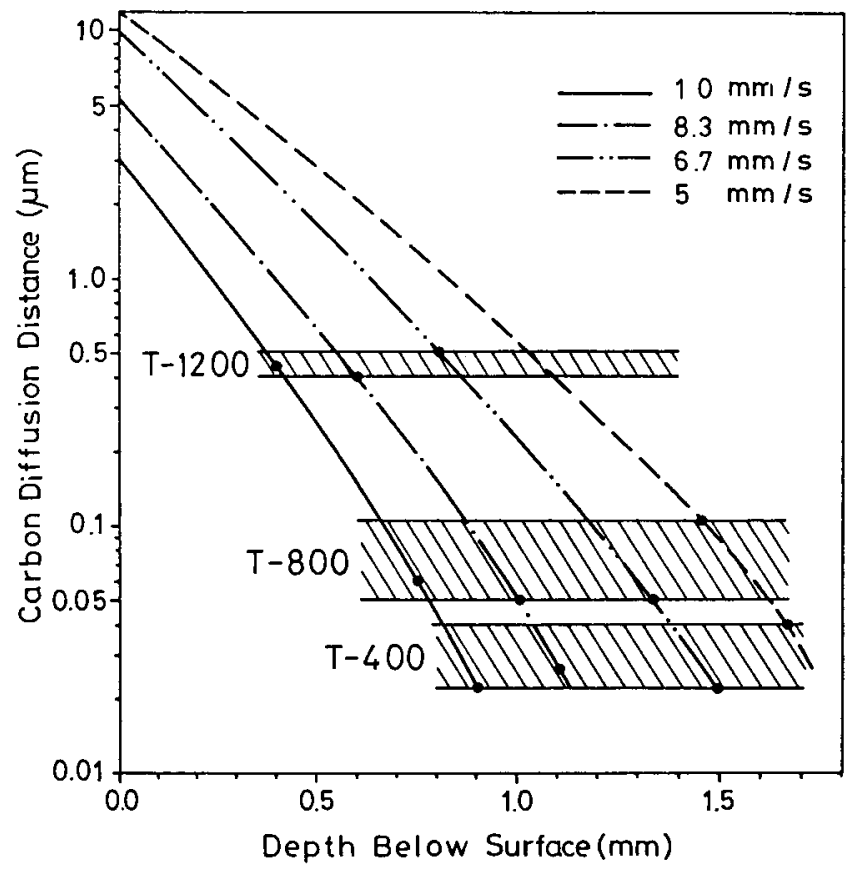

Fig. 8 - The correlation between the theoretical carbon diffusion distance and the depth of laser-hardened zones. The shaded area represents values of the experimental measurements.

time than did the region further from the surface. The higher the austenitizing temperature, the larger the resulting grain size of austenite (transformed to martensite upon self-quenching). Therefore, as shown in Figures 5 and 6 , the sizes of martensite lath and twin decreased with the increasing distance below the surface.

There are two general types of ferrous martensites, e.g., dislocated laths (for $C<0.3 \mathrm{wt}$ pct) and twinned plates (for $C>0.6 \mathrm{wt}$ pct). ${ }^{[18,19]}$ Nutting ${ }^{[20]}$ reviewed some important factors in controlling the martensite substructure, where the composition (or local chemistry), $M_{s}$ temperature (affected by the composition), and cooling rate (affected $M_{s}$ and dislocation density of martensite) were considered to have great influence on the laser surface treatment. For 4340 steel, both types of martensites were observed in the quenched alloy.

According to Andrew's Eq. [21] dealing with rapid heat treatments, the calculated $M_{s}$ temperature of 4340 is approximately $313^{\circ} \mathrm{C}$. Autotempered martensite could form in the cooling cycle due to $\varepsilon$-carbide precipitation at dislocation networks. ${ }^{[22]}$ This phenomenon was observed in the oil-quenched 4340 specimens. Similar observations have been found in the laser-treated specimens, although a rapid cooling rate during the process is involved, i.e., a very short reaction time for precipitation.

\section{E. Microstructures in the Transition Zone}

The nucleation of austenite from ferrite-carbide aggregates during heating occurs primarily at carbide interfaces. ${ }^{[6,7]}$ Growth from these carbides proceeds until they are completely enveloped, and the subsequent growth is due to the diffusion of carbon through austenite. In alloy steels, the alloying elements such as $\mathrm{Cr}$ and $\mathrm{Mn}$ were partitioned to cementite; moreover, it was reported that these alloying elements retarded on the dissolution of the alloyed carbide. ${ }^{[16,17]}$

The actual peak temperature in the transition zone might be higher than $\mathrm{Ac}_{3}$, but the time for complete austenitization was insufficient. As a result, the structures were comprised of either partially dissolved carbides with austenite envelopes or isolated austenite islands in the matrix of a relatively low carbon martensite (Figure 7). Austenite formed at carbide interfaces at high temperatures was retained upon cooling owing to the presence of the higher concentration of austenite stabilizing elements (e.g., C, Cr, Mn) in the envelopes. For T-400 and $\mathrm{T}-800$ specimens, the size of carbides was relatively fine and the transformation products were too difficult to be examined by TEM. However, it is believed that a similar transformation behavior could be involved, except in a very narrow range of the transition zone.

\section{CONCLUSIONS}

1. Under complete austenitization conditions during laser transformation hardening, the faster scan rate caused the smaller martensite sizes (lath and twin) and the less autotempering effect in the surface layer. The surface hardness was also higher for specimens scanned by laser at a faster speed.

2. The tempering temperature of the steel played an important role in controlling the carbide size. The lower tempering temperature, the deeper hardened zone, and the narrower transition zone in the hardness profile of the laser-treated specimen were obtained.

3. Microstructures in the hardened zone of laser-treated specimens were similar to those of the conventional oil-quenched ones. The structures consisted of mainly lath martensite (with retained austenite at lath boundaries) and plate (twinned) martensite. Autotempered martensite was observed more frequently in the specimens with lower scan rates. However, the structures in the transition zone consisted of partially dissolved carbides with austenite envelopes and/or isolated austenite islands in the matrix of relatively low carbon martensite.

4. A simple mathematical calculation was used to estimate the carbon diffusion distance in austenite during laser surface treatments, and the calculated results were in reasonably good agreement with the experimental measurements in hardness and microstructural observations.

\section{ACKNOWLEDGMENTS}

Appreciation is expressed to Dr. S.L.I. Chan for critical comments on the manuscript. The authors gratefully acknowledge the support of the Republic of China National Science Council (Contract No. NSC 78-0405E002-15).

\section{REFERENCES}

1. J. Mazumder: J. Met., 1983, vol. 35 (5), pp. 18-26.

2. H.B. Singh, S.M. Copley, and M. Bass: Metall. Trans. A, 1981, vol. $12 \mathrm{~A}$, pp. $138-40$. 
3. A.N. Safonov, V.M. Tarasenko, A.F. Baskov, A.A. Nikitin, I.V. Lyasotskii, and E.V. Safonov: Metalloved. Term. Obrab. Met., 1985 , no. 4, pp. 5-9.

4. C. Chen: Chin. J. Mater. Sci., 1986, vol. 18A (2), pp. 70-77.

5. G. Molinder: Acta Metall., 1956, vol. 4, pp. 565-71.

6. R.R. Judd and H.W. Paxton: Trans. AIME, 1968, vol. 242, pp. 206-13.

7. G.R. Speich and A. Szirmae: Trans. AIME, 1969, vol. 245, pp. 1063-73.

8. G.R. Speich, V.A. Demarest, and R.L. Miller: Metall. Trans. A, 1981 , vol. 12A, pp. 1419-28.

9. M.F. Ashby and K.E. Easterling: Acta Metall., 1984, vol. 32, pp. $1935-48$.

10. H.J. Hegge and J.Th.M. De Hosson: Scripta Metall., 1987, vol. 21 , pp. 1737-42.

11. R.A. Grange: Trans. AIME, 1966, vol. 59, pp. 26-48.

12. A. Solina, M.D. Sanctis, L. Paganini, A. Blarasin, and S. Quaranta: J. Heat Treat., 1984, vol. 3 (3), pp. 193-204.
13. F.F. Vaughn, V.R. Farlow, and E.R. Meyer: Trans. ASM, 1942 , vol. 30 , pp. 516-40.

14. S. Kou, D.K. Sun, and Y.P. Le: Metall. Trans. A, 1983, vol. 14A, pp. 643-53.

15. O.A. Sandven: Int. Laser Processing Conf., Anaheim, CA, Nov. 16-17, 1981, pp. 1-19.

16. J.R. Bradley and S. Kim: Metall. Trans. A, 1988, vol. 19A, pp. 2013-25.

17. J.R. Bradley and D. Kim: Scripta Metall., 1989, vol. 23, pp. 131-36.

18. G. Krauss and A.R. Marder: Metall. Trans., 1971, vol. 2, pp. 2343-57.

19. Gareth Thomas: Metall. Trans., 1971, vol. 2, pp. 2373-85.

20. J. Nutting: J. Iron Steel Inst., 1969, vol. 6, pp. 872-93.

21. M. Melander and J. Nicolov: J. Heat Treat., 1985, vol. 4 (1), pp. 32-38.

22. Earl R. Parker: Metall. Trans. A, 1977, vol. 8A, pp. 1025-42. 